\title{
PREVALENCE OF ANXIETY AND DEPRESSION IN PATIENT WITH CHRONIC OBSTRUCTIVE PULMONARY DISEASE
}

\author{
Sharma $S^{1}$, Shakya $U^{2}$, Gorkhali $B^{3}$, Neupane $S^{4}$
}

${ }^{1}$ Neuro Cardio and Multispeciality Hospital, Biratnagar, Nepal, ${ }^{2}$ Innovative college of health sciences, Kathmandu, Nepal, ${ }^{3}$ Lecturer, Nepal Institute of Health Sciences, Kathmandu, Nepal, ${ }^{4}$ Institute of Medicine, Biratnagar Nursing Campus, Biratnagar, Nepal

\begin{abstract}
Anxiety and depression are very common comorbidities in patients with chronic obstructive pulmonary disease (COPD). This study was aimed at documenting the prevalence anxiety and depression in COPD patient attending tertiary level hospital. A quantitative cross sectional analytical study was carried out in 221 patients with previously diagnosed COPD. Participants were recruited from respiratory OPD at Tribhuvan University Teaching Hospital, Nepal. Anxiety and depression were screened using previously validated Nepalese version of Hospital Anxiety and Depression Scale (HADS) and dyspnea was assessed using the modified Medical Research Council Dyspnea Scale (mMRC). COPD Assessment Test (CAT) was used to measure the impact of COPD on daily life. Data was analyzed using SPSS version 16. Out of 221, 140 patients (63.3\%) had anxiety and 153 patients (69.2\%) had depression and 133 (60.2\%) had both psychiatric symptoms. Factors associated with anxiety and depression in COPD patients were age, ethnicity, educational status, marital status, current working status, duration of illness, history of previous hospitalization, number of hospitalization in previous year, domiciliary oxygen therapy comorbidities along with dyspnea, CAT score. In conclusion, the study findings suggest that anxiety and depression are highly prevalent in COPD patients.
\end{abstract}

\section{KEYWORDS}

Anxiety, COPD, Depression, dyspnea scale, HADS, mMRC

\section{CORRESPONDING AUTHOR}

Sita Sharma,

Neuro Cardio Multispecialty Hospital,

Biratnagar, Nepal

Email: sharma.sita67@gmail.com 


\section{INTRODUCTION}

Chronic obstructive pulmonary disease (COPD) is defined as a disease state characterized by the presence of airflow obstruction due to chronic bronchitis or emphysema; the airflow obstruction is generally progressive, may be accompanied by airway hyperactivity, and may be partially reversible. ${ }^{1}$ Globally around 65 million people are reported to suffer from moderate to severe COPD. Furthermore, COPD is currently fifth leading cause of death word wide and expected to rise to third by $2020 .^{2}$ Therefore, it is evident that increasing number of people is suffering from this disease and psychosocial consequences. ${ }^{3}$

Persons with COPD have a high prevalence of psychological disorders and may function at a reduced level of efficiency due to neuropsychological impairments. Psychological status is independently related to all dimensions of health-related quality of life. Anxiety and depression are very common comorbidities in COPD and have significant impact on patients, their families, society, and the course of the disease ${ }^{4-6}$ Estimates of prevalence of anxiety and depression in COPD are generally higher than those reported in some other advanced chronic diseases. Screening for depression and anxiety may help to identify patients with poor quality of life and an urgent need for intervention in order to improve their health status. ${ }^{7}$

Untreated and undetected anxiety and depressive symptoms may increase physical disability, morbidity, and health-care utilization. ${ }^{8}$ While few published studies demonstrate that these disorders associated with COPD respond well to appropriate pharmacologic and non-pharmacologic therapy, only a small proportion of COPD patients with these disorders receive effective treatment. ${ }^{7,9}$ Anxiety and depression are challenging to identify and treat because their symptoms often overlap with those of COPD. The causes of depression and anxiety symptoms are multifactorial and include behavioral, social and biological factors. ${ }^{10}$

It has been argued that family may play a significantly important role in COPD given the higher prevalence of depression and anxiety in these patient populations and their association with important clinical features such as dyspnea. It has also been documented that unsupportive family relationships were associated with psychological distress. ${ }^{11}$

A cross-sectional population-based postal survey of COPD patients revealed association of depression and anxiety with demographic, health-related quality of life and clinical characteristics of COPD patients seen in UK primary care. ${ }^{12}$ Depression is also associated with lower patient-reported generic health status. The data suggest that assessment and treatment for depression and anxiety should be considered for all COPD patients, not just those with more severe clinical levels of disease. ${ }^{13}$
Though anxiety and depression are significant comorbid conditions in chronic illnesses, little is known about the prevalence or risk factors for anxiety or depressive symptoms in patient with COPD. Thus it is important to identify those who have clinically significant anxiety or depressive symptoms and its associated factors.

\section{MATERIALS AND METHODS}

This was a cross-sectional analytical study conducted on 221 patients diagnosed with at the Outpatient department of Tribhuvan University Teaching Hospital (TUTH), Kathmandu, Nepal. Data was collected following an ethical approval from the Research Committee Maharajgunj Nursing Campus and Institutional Review Board of Tribhuvan University; Institute of Medicine. The sample size for this study was calculated based on similar study by our group. ${ }^{14}$ After obtaining the formal permission from the hospital, purpose of the study was explained to the patient and they were explained about the study. Following this, an informed consent was obtained from each participant who met the inclusion criteria. Participant's confidentiality was maintained by using coding their personal identity information in all forms, and the information obtained was solely used for research purpose. The average time required to complete the interview was about 15-20 minutes following the familiarization. A structured interview based questionnaire was use to collect the information regarding the sociodemographic and disease and treatment related variables of the patient such as age, sex, address, ethnicity, religion, educational status, marital status, type of family, working status, smoking status, type of fuel used for cooking, and history of COPD in family, duration of illness, history of previous hospitalization, status of hospitalization in last year, currently used medicine, domiciliary oxygen therapy and other comorbidities. Anxiety and depression were screened using hospital anxiety depression rating scale. Dyspnea level was measured using modified Medical Research Council Dyspnea Scale. Impact of COPD on activities of daily living was assessed using COPD assessment Test (CAT).

\section{Data Analysis Procedure}

The collected data were checked daily and organized for completeness and accuracy. The collected data were then edited, coded, classified and then entered into Excel spreadsheet, which was later transferred to SPSS (Statistical Package for Social Science) version 16. Descriptive statistics such as frequency and percentages were used for categorical variables and mean and standard deviation was used for continuous variables. The relationship of various factors with anxiety and depression was analysed using chi-square test. Logistic regression was done to find out the most significant associated factor to anxiety and depression. The significance level (alpha) was set at 0.05 and a $p$ value $<0.05$ was considered to be statistically significant. 


\section{RESULTS}

221 patients diagnosed with COPD were included in the study. The mean age of patients was $68.16 \pm 10$. 16 years and their age ranged from 44 to 90 years. Less than half of the patients $(46.2 \%)$ were male. Regarding the ethnic group more than half (54.7\%) of patient were from upper caste. Similarly, majority of patients $143(64.7 \%)$ COPD were illiterate and most of the COPD patients (67.4\%) were married. Regarding occupation, only 51 (23.1\%) was involved in occupation currently. Likewise, 15.4\% COPD patients were current smokers, less than half (42.5\%) COPD patients had history of exposure to passive smoking. The mean duration of illness was $6.99 \pm 6.34$ Years, $57 \%$ had previously hospitalized and $27.8 \%$ had no any history of hospitalization in last year. Among COPD patients majority of patients $79.2 \%$ weren’t dependent on domiciliary oxygen and only 53 patients had other comorbidities.

95.2\% patients presented with complaints of Dyspnea. Dyspnea was measured using modified medical research council grading (mMRC). 16 patients $(7.2 \%)$ were in mMRC grade 0,46 patients (20.8\%) were in mMRC grade 1, 41 patients (18.6\%) in mMRC grade 2,72 patients (32.6\%) in mMRC grade 3 and 46 patients (20.8\%) in mMRC grade 4.

Out of 221 patients, 140 patients (63.3\%) had anxiety and 152 patients $(69.2 \%)$ had depression. These patients had a HADS score of 8 or more than 8.133 patients (60.2\%) had both anxiety and depression using HADS scale (Table 1).

\begin{tabular}{|c|c|c|}
\hline Variables & $\mathbf{n}$ & $\%$ \\
\hline \multicolumn{3}{|l|}{ Anxiety } \\
\hline Present & 140 & 63.3 \\
\hline Absent & 81 & 36.7 \\
\hline \multicolumn{3}{|l|}{ Level of Anxiety } \\
\hline Normal condition (Score $0-7$ ) & 81 & 36.7 \\
\hline $\begin{array}{l}\text { Border line disorder (Score } \\
\text { 8-10) }\end{array}$ & 19 & 8.6 \\
\hline Abnormal case (Score 11-21) & 121 & 54.7 \\
\hline \multirow{2}{*}{\multicolumn{3}{|c|}{$\begin{array}{l}\text { Mean of Total Score: } 11.37 \pm 6.89 \\
\text { Depression }\end{array}$}} \\
\hline & & \\
\hline Present & 153 & 69.2 \\
\hline Absent & 68 & 30.8 \\
\hline \multicolumn{3}{|l|}{ Level of Depression } \\
\hline Normal condition (Score 0-7) & 69 & 31.2 \\
\hline $\begin{array}{l}\text { Border line disorder (Score } \\
\text { 8-10) }\end{array}$ & 38 & 17.2 \\
\hline Abnormal case (Score 11-21) & 114 & 51.6 \\
\hline \multicolumn{3}{|l|}{ Mean of Total Score: $11.18 \pm 6.01$} \\
\hline \multicolumn{3}{|l|}{ Both anxiety and depression } \\
\hline Present & 133 & 60.2 \\
\hline Absent & 88 & 39.8 \\
\hline
\end{tabular}

Factors which were significantly associated ( $p$ value $<0.05$ ) with anxiety in COPD patients were patient's age $(p=0.003)$, ethnicity $(p=0.002)$, educational status $(\mathrm{p}=0.014)$, marital status $(p=0.002)$, current working status $(p=0.015)$, duration of illness $(p<0.001)$, history of previous hospitalization $(\mathrm{p}=0.010)$, number of hospitalizations in the previous year $(\mathrm{p}=0.020)$, domiciliary oxygen therapy $(p<0.001)$, presence of other comorbodities $(p=0.034)$, mMRC grade $(p<0.001)$ and CAT score $(p<0.001)$, (Table 2$)$.

Table 2: Association between Socio-Demographic and Clinical Variable of Respondents and Anxiety $(n=129)$

\section{Anxiety}

Variables

Age Groups (in years)

Less than 60

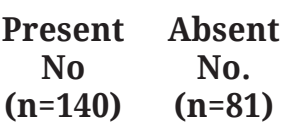

Chisquare $p$ value

60-69

70 and more 36

0.003

31

31

73

Sex

Male

60

42

0.196

Female

80

Ethnicity

Upper caste

0.002

Other

Education status

Literate

41

37

0.014

Illiterate

Marital status

Married

84

65

0.002

Widow/Widower

56

16

Occupation

Currently working

0.015

Currently not

working

\section{Smoking Status}

Current smoker

Ex-smoker

19

15

0.577

Non-smoker

91

Duration of

Illness

Less than 10 Years

97

75

$<0.001$

More than 10 years
43

6

Table continues to the next page... 
Table continued from the previous page...

\begin{tabular}{|c|c|c|c|}
\hline \multicolumn{4}{|c|}{ History of previous hospitalization } \\
\hline Yes & 89 & 37 & \multirow[t]{2}{*}{0.010} \\
\hline No & 51 & 44 & \\
\hline \multicolumn{4}{|c|}{ No. of hospitalization in previous year $(n=126)$} \\
\hline Less than 2 times & 63 & 33 & \multirow[t]{2}{*}{0.020} \\
\hline 2 and more times & 26 & 4 & \\
\hline \multicolumn{4}{|l|}{$\begin{array}{l}\text { Domiciliary } \\
\text { Oxygen therapy }\end{array}$} \\
\hline Yes & 41 & 5 & \multirow[t]{2}{*}{$<0.001$} \\
\hline No & 99 & 76 & \\
\hline \multicolumn{4}{|l|}{$\begin{array}{l}\text { Other } \\
\text { co-morbidities }\end{array}$} \\
\hline Present & 40 & 13 & \multirow[t]{2}{*}{0.036} \\
\hline Absent & 100 & 68 & \\
\hline \multicolumn{4}{|c|}{ MRC Dyspnea Score } \\
\hline 0 & 1 & 15 & \multirow[t]{5}{*}{$<0.001$} \\
\hline 1 & 9 & 37 & \\
\hline 2 & 26 & 15 & \\
\hline 3 & 61 & 11 & \\
\hline 4 & 43 & 3 & \\
\hline \multicolumn{4}{|c|}{$\begin{array}{l}\text { Impact of COPD on daily } \\
\text { activities (CAT) }\end{array}$} \\
\hline No impact & 0 & 1 & \multirow[t]{5}{*}{$<0.001$} \\
\hline Low impact & 1 & 12 & \\
\hline Medium Impact & 23 & 46 & \\
\hline High impact & 70 & 17 & \\
\hline Very high impact & 46 & 5 & \\
\hline
\end{tabular}

Further analysis using binary logistic regression showed that age, current working stats and dyspnea score were independently associated with anxiety. Age was associated with an OR of 1.26 ( $p=0.014$, $95 \% \mathrm{CI}=1.04-1.53)$. Currently working patients were 7.67 times ( $p=0.029,95 \%$ CI 0.71 to 82.12 ) more likely to have anxiety symptoms than patients with no current occupation. Similarly dyspnea score was also associated with an odds of 0.23 ( $p=0.004,95 \%$ CI 0.08-0.63) (Table 3).

Similarly, factors associated ( $p$ value $<0.05)$ with depression in COPD patients were patient's age $(p=0.001)$, marital status $(p=0.001)$, current working status $(p=0.015)$, smoking status $(p=0.034)$, duration of illness $(p=0.001)$, history of previous hospitalization ( $p=0.002$ ), number of hospitalizations in the previous year $(\mathrm{p}=0.040)$, domiciliary oxygen therapy $(p<0.001)$, presence of other comorbodities $(p=0.008)$, mMRC grade $(p<0.001)$ and CAT score $(\mathrm{p}<0.001)$, (Table 4).
Table 4: Association between Socio-Demographic and clinical variables of Respondents and Depression $(\mathrm{n}=129)$

Depression

Variables

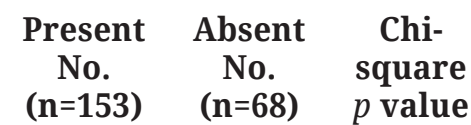

Age Groups (in years)

Less than 60

22

0.001

60-69

29

More than 70

33

17

Sex

Male

69

33

0.637

Female

84

35

Ethnicity

Upper caste

82

38

0.753

Other

71

30

Education status

Literate

49

29

0.127

Illiterate

104

39

Marital status

Married

$92 \quad 57$

0.001

Widow/Widower

61

11

Occupation

Currently working $\quad 28 \quad 23$

Currently not

working

125

Smoking Status

Current Smoker

$18 \quad 16$

Ex-smoker

104

35

Non-smoker

31

Duration of Illness

Less than 10 Years

110

62

0.001

10 and more

43

6

History of previous hospitalization

Yes

$98 \quad 28$

0.002

No

$55 \quad 40$

No. of hospitalization in previous year

Less than 2 times

$71 \quad 25$

0.040

2 and more times

27

3

Domiciliary Oxygen therapy

Yes

$$
41
$$

5

$<0.001$

No

112

63

Other co-morbidities

Present

$\begin{array}{cc}44 & 9 \\ 109 & 59\end{array}$

Table continues to the next page... 
Table continued from the last page...

\begin{tabular}{|lccc|} 
MRC Dyspnea Score & & & \\
0 & 1 & 15 & $<0.001$ \\
1 & 13 & 33 & \\
2 & 27 & 14 & \\
3 & 68 & 4 & \\
4 & 44 & 2 & \\
Impact of COPD on & & & \\
daily activities (CAT) & & & \\
No impact & 0 & 1 & $<0.001$ \\
Low impact & 3 & 10 & \\
Medium impact & 26 & 43 & \\
High impact & 76 & 11 & \\
Very high impact & 48 & 3 & \\
\hline
\end{tabular}

Likewise, further analysis using binary logistic regression showed that age, current working status, use of domiciliary oxygen therapy and dyspnea score were independently associated with depression. Age was associated with an OR of $1.34(p=0.026,95 \%$ CI $=0.98-1.83$ ). Currently working patients were 36.35 ( $p=0.043$, 95\% CI 0.71 to 82.12 ) times more likely to have depressive symptoms than patient with no current occupation. Patients with domiciliary oxygen therapy were 32.41 ( $p=0.020,95 \%$ CI 1.71 to 612.71) times likely to have symptoms of depression. Similarly dyspnea score was also associated with an odd of 0.082 ( $p=0.004,95 \%$ CI 0.01-0.45) (Table 5).

\section{DISCUSSION}

The study aimed to describe prevalence of anxiety and depression among COPD patients. The study demonstrated out of 221 patients, 140 patients (63.3\%) had anxiety and 152 patients (69.2\%) had depression. The mean HADS $( \pm S D)$ anxiety score was 11.37 ( \pm 6.894) and mean HADS $( \pm$ SD) depression score was 11.18 ( \pm 6.013). This finding is nearly consistent with the findings of the study including 60 COPD patients which show the mean scores for anxiety and depression were $8.2 \pm 4.6$ and $7.9 \pm 4.3$ respectively. Likewise in their study, $41.7 \%$ patients

Table 3: Most Significant associated factor for anxiety among COPD patient by logistic regressions $(\mathrm{n}=221)$

\begin{tabular}{|c|c|c|c|c|c|c|}
\hline \multirow[t]{2}{*}{ Variables } & \multirow[t]{2}{*}{ B } & \multirow[t]{2}{*}{ S.E. } & \multirow{2}{*}{$\begin{array}{l}\text { Adjusted odds } \\
\text { Ratio ( } \beta)\end{array}$} & \multicolumn{2}{|c|}{$95 \% \mathrm{CI}$} & \multirow[t]{2}{*}{$p$ value } \\
\hline & & & & Lower & Upper & \\
\hline Age & 0.236 & 0.097 & 1.266 & 1.048 & 1.530 & 0.014 \\
\hline \multicolumn{7}{|l|}{ Sex } \\
\hline Male & -0.379 & 0.847 & 0.685 & 0.130 & 3.604 & 0.655 \\
\hline Female & Ref & Ref & Ref & Ref & Ref & \\
\hline \multicolumn{7}{|l|}{ Ethnicity } \\
\hline Upper caste & 0.482 & 0.651 & 1.620 & 0.452 & 5.808 & 0.459 \\
\hline Other & Ref & Ref & Ref & Ref & Ref & \\
\hline \multicolumn{7}{|l|}{ Education status } \\
\hline Literate & 0.098 & 0.915 & 1.103 & 0.184 & 6.625 & 0.915 \\
\hline Illiterate & Ref & Ref & Ref & Ref & Ref & \\
\hline \multicolumn{7}{|l|}{ Marital status } \\
\hline Married & -0.099 & 0.793 & 0.905 & 0.191 & 4.283 & 0.900 \\
\hline Widow/Widower & Ref & Ref & Ref & Ref & Ref & \\
\hline \multicolumn{7}{|l|}{ Occupation } \\
\hline Currently working & 2.038 & 1.209 & 7.676 & 0.717 & 82.122 & 0.029 \\
\hline Currently not working & Ref & Ref & Ref & Ref & Ref & \\
\hline Duration of Illness & -0.072 & 0.101 & 0.930 & 0.763 & 1.134 & 0.473 \\
\hline \multicolumn{7}{|c|}{ Domiciliary Oxygen therapy } \\
\hline Yes & 0.801 & 0.875 & 2.229 & 0.401 & 12.393 & 0.360 \\
\hline No & Ref & Ref & Ref & Ref & Ref & \\
\hline \multicolumn{7}{|l|}{ Other co-morbidities } \\
\hline Present & 0.660 & 0.726 & 1.935 & 0.466 & 8.032 & 0.363 \\
\hline Absent & Ref & Ref & Ref & Ref & Ref & \\
\hline mMRC Dyspnea Score & -1.447 & 0.504 & 0.235 & 0.088 & 0.631 & 0.004 \\
\hline CAT Score & -0.075 & 0.073 & 0.928 & 0.804 & 1.072 & 0.310 \\
\hline
\end{tabular}


Table 5: Most Significant associated factor for Depression among COPD Patient by logistic regressions ( $\mathrm{n}=221$ )

\begin{tabular}{|c|c|c|c|c|c|c|}
\hline \multirow{2}{*}{ Variables } & \multirow{2}{*}{ B } & \multirow{2}{*}{ S.E. } & \multirow{2}{*}{$\begin{array}{l}\text { Adjusted odds } \\
\text { Ratio }(\beta)\end{array}$} & \multicolumn{2}{|c|}{$95 \% \mathrm{CI}$} & \multirow{2}{*}{$p$ value } \\
\hline & & & & Lower & Upper & \\
\hline Age & 0.295 & 0.158 & 1.343 & 0.985 & 1.830 & 0.026 \\
\hline \multicolumn{7}{|l|}{ Sex } \\
\hline Male & -0.246 & 1.177 & 0.782 & 0.078 & 7.844 & 0.834 \\
\hline Female & Ref & Ref & Ref & Ref & Ref & \\
\hline \multicolumn{7}{|l|}{ Ethnicity } \\
\hline Upper caste & 1.121 & 0.953 & 3.067 & 0.474 & 19.861 & 0.240 \\
\hline Other & Ref & Ref & Ref & Ref & Ref & \\
\hline \multicolumn{7}{|l|}{ Education status } \\
\hline Literate & -1.392 & 1.142 & 0.249 & 0.027 & 2.332 & 0.223 \\
\hline Illiterate & Ref & Ref & Ref & Ref & Ref & \\
\hline \multicolumn{7}{|l|}{ Marital status } \\
\hline Married & -0.368 & 1.062 & 0.692 & 0.086 & 5.545 & 0.729 \\
\hline Widow/Widower & Ref & Ref & Ref & Ref & Ref & \\
\hline \multicolumn{7}{|l|}{ Occupation } \\
\hline Currently working & 3.593 & 1.778 & 36.352 & 1.114 & 1.186 & 0.043 \\
\hline Currently not working & Ref & Ref & Ref & Ref & Ref & \\
\hline Duration of Illness & -0.243 & 0.150 & 0.785 & 0.585 & 1.052 & 0.105 \\
\hline \multicolumn{7}{|l|}{$\begin{array}{l}\text { Domiciliary Oxygen } \\
\text { therapy }\end{array}$} \\
\hline Yes & 3.479 & 1.500 & 32.418 & 1.715 & 612.715 & 0.020 \\
\hline No & Ref & Ref & Ref & Ref & Ref & \\
\hline \multicolumn{7}{|l|}{ Other co-morbidities } \\
\hline Present & -0.616 & 0.991 & 0.540 & 0.077 & 3.766 & 0.534 \\
\hline Absent & Ref & Ref & Ref & Ref & Ref & \\
\hline mMRC Dyspnea Score & -2.497 & 0.869 & 0.082 & 0.015 & 0.453 & 0.004 \\
\hline CAT Score & -0.122 & 0.101 & 0.885 & 0.727 & 1.078 & 0.226 \\
\hline
\end{tabular}

had symptoms suggestive of anxiety and $46.7 \%$ had symptoms suggestive of depression..$^{15}$ However a study conducted by Puhan et al. among 88 COPD patients and Janssen et al, among 701 COPD patients show the mean HADS depression score as $7.63 \pm 3.9$ and $7.2 \pm 0.2$, whereas $21.6 \%$ and $32.1 \%$ patients had scores $\geq 11$ for depression respectively.6, 16 For the HADS anxiety domain, mean score was $7.03 \pm 4.0$ and $7.6 \pm 0.2$ and $22.7 \%$, and $27.4 \%$ patients had scores $\geq 11$ respectively.

A cross-sectional association was observed for anxiety/depression with different sociodemographic and clinical variables. Both anxiety and depression were associated with age $(p=0.003$, $p=0.001$ ) and were more prevalent in age group $\leq 70$ years. This finding was supported by the study from Ray et al. VAT is a relatively common problem but in comparison to ventilator-associated pneumonia (VAP where age is associated with anxiety and depression. ${ }^{17}$ In contrast, the age of the patient did not appear to be associated with both anxiety and depression in a study by Jose et $\mathrm{al}^{18}$ Similarly in another study, compared with the oldest group ( $\geq 70$ years old), the risk of anxiety and depression was $15 \%$ higher for those aged $\leq 50$ years of age; those aged 51-70 also had an excess risk of $11 \%$. Furthermore, in the present study higher number females score both in anxiety and depression scale than males, however there was no statistical significant relation between the scores of anxiety/ depression and gender. In a study by Xiao et al, it was reported that after adjustment for covariates, female patients were more likely to suffer from anxiety (aOR $=6.41,95 \%$ CI: 1.73-23.80) than male patients. ${ }^{19}$

Likewise, we found anxiety was associated with ethnicity $(p=0.002)$, educational status $(p=0.014)$, marital status $(p=0.002)$ and occupational status $(p=0.015)$ whereas depression was associated with marital status $(p=0.001)$, working status $(p=0.015)$ and smoking status $(\mathrm{p}=0.034)$. Balcells et al, 2010 also found that strong association between the working 
status and presence of anxiety. ${ }^{20} \mathrm{~A}$ Korean study on the prevalence of depression and anxiety noted that smoking history were independent risk factors for depression in patients with COPD. ${ }^{21}$ Further current smokers had a higher prevalence of both anxiety ( $54 \%$ vs. $37 \%$ ) and depression ( $43 \%$ vs. $23 \%$ ) than nonsmokers. ${ }^{22}$ Some studies also found that living alone and low education levels were related to anxiety and depression in COPD. ${ }^{23,24} \mathrm{~A}$ cross-sectional study from India gave a strong relationship with low level of education, poor socio-economic conditions and advanced age to depression. ${ }^{25}$ Likewise Tsai et al., population-based studies on the association between chronic obstructive pulmonary disease (COPDfound in their study that age, gender, monthly income and hospitalization were significantly related to the risk of depression in COPD patients. Compared with the oldest group ( $\geq 70$ years old), the risk of depression was $15 \%$ higher for those aged $\geq 50$ years of age; those aged 51-70 also had an excess risk of 11\%.26 In another study, depression was related to the severity of pulmonary obstruction and anxiety was related to marital status and satisfaction with income. ${ }^{22}$ Further anxiety was more common in women than in men ( $47 \%$ vs. $34 \%)$ and current smokers had a higher prevalence of both anxiety (54\% vs. $37 \%$ ) and depression (43\% vs. $23 \%$ ) than non-smokers. ${ }^{22}$ A cross sectional study among 121 COPD patients in Aligarh, India to assess the presence of anxiety and depression in COPD client attending OPD using Hospital anxiety and depression scale to examine depression and anxiety respectively showed that $69(57.02 \%)$ and $44(36.37 \%)$ patients out of $121 \mathrm{had}$ depression and anxiety respectively. In addition, depression was more common in male gender, and this prevalence was also found to be positively associated with lower education class, social class, single marital status and cases residing urban locality. Likewise, prevalence of anxiety was more in female gender, rural locality, higher education and upper socioeconomic and marital status being single. ${ }^{27}$

The present study showed that the age, current working status, use of domiciliary oxygen and mMRC Dyspnea score were the most significant factors associated with anxiety and depression in COPD. The factors associated with anxiety and depression in COPD patients were found same in the findings reported by Jose et al. These include duration of disease, number of hospitalizations in the previous year MMRC grade, oxygen therapy, and presence of other comorbodities.18 Another study also reported that comorbidity, increased duration of disease diagnosis, increased dyspnea, increases the risk of depression in COPD patients. ${ }^{23,26}$

The major limitations were absence of specialist evaluation for anxiety/depression and it was difficult to assume causality for anxiety and depression as it was a cross-sectional study.

In conclusion, the prevalence of anxiety and depression in chronic obstructive pulmonary disease is very high and a significant number of patients have both the co-morbidities. Age, current working status, use of domiciliary oxygen and dyspnea score were the most significant factor associated with anxiety and depression in COPD. Considering the high prevalence of anxiety and depression among COPD patients, management of the psychiatric symptoms should be incorporated in the treatment of COPD. A routine screening test is recommended to detect the psychiatric morbidities among the COPD patients.

\section{REFERENCES:}

1. American Thoracic Society. Annual Report. 20132014. Retrieved from https://www.thoracic.org/ about/resources/ats-annual-report-2013-2014.pdf

2. World Health Organization. Fact Sheet:Chornic obstructive Pulmonary Disease. 2015. Retreived from http://www.who.int/en/news-room/fact-sheets/ detail/chronic-obstructive-pulmonary-disease(copd)

3. Cafarella PA, Effing TW, Barton C, Ahmed D, Frith PA. Management of depression and anxiety in COPD. European Respiratory Monograph 2013; 59: 144-63.

4. Hynninen KMJ, Breitve MH, Wiborg AB, Pallesen S, Nordhus IH. Psychological characteristics of patients with chronic obstructive pulmonary disease: a review. J Psychosom Resc 2005; 59: 429-43.

5. Gudmundsson G, Gislason $\mathrm{T}$, Janson $\mathrm{C}$ et al. Depression, anxiety and health status after hospitalisation for COPD: a multicentre study in the Nordic countries. Respir Med 2006; 100: 87-93.

6. Janssen DJ, Spruit MA, Leue C et al. Symptoms of anxiety and depression in COPD patients entering pulmonary rehabilitation. Chron Respir Dis 2010; 7: 147-57.

7. Pumar MI, Gray CR, Walsh JR, Yang IA, Rolls TA, Ward DL. Anxiety and depression-Important psychological comorbidities of COPD. J Thorac Dis 2014; 6: 1615-31.

8. Cuneyt Tetikkurt IO, Seza Tetikkurt, Nail Yllmaz, Turan Ertan, Nihal Bayar. Anxiety and depression in COPD patients and correlation with sputum and BAL cytology. Multidisciplinary Resp Med 2011; 6: 226-31.

9. Salerno FG, Carone M. Anxiety and depression in COPD. Multidisciplinary Resp Med 2011; 6: 212-3.

10. Yohannes AM, Alexopoulos GS. Depression and anxiety in patients with COPD. Eur Respir Rev 2014; 23: 345-9.

11. Holm KE, Plaufcan MR, Ford DW et al. The impact of age on outcomes in chronic obstructive pulmonary disease differs by relationship status. J Behav Med 2014; 37: 654-63. 
12. Cleland JA, Lee AJ, Hall S. Associations of depression and anxiety with gender, age, health-related quality of life and symptoms in primary care COPD patients. Fam Pract 2007; 24: 217-23.

13. Dua R, Das A, Kumar A, Kumar S, Mishra M, Sharma K. Association of comorbid anxiety and depression with chronic obstructive pulmonary disease. Lung India 2018; 35: 31-6.

14. Sharma S, Shakya U, Sharma P, Limbu P Association between Psychological Status and Dyspnea in Patients with Chronic Obstructive Pulmonary Disease. J Biomed Pharmaceutical Resc 2017; 6: 4352.

15. Tetikkurt C, Ozdemir I, Tetikkurt S, Yilmaz N, Ertan T, Bayar N. Anxiety and depression in COPD patients and correlation with sputum and BAL cytology. Multidisciplinary Resp Med 2011; 6: 22631.

16. Puhan MA, Frey M, Buchi S, Schunemann HJ. The minimal important difference of the hospital anxiety and depression scale in patients with chronic obstructive pulmonary disease. Health Qual Life Outcomes 2008; 6: 46.

17. Bajpai J, Prakash V, Kant S et al. Study of oxidative stress biomarkers in chronic obstructive pulmonary disease and their correlation with disease severity in north Indian population cohort. Lung India 2017; 34: 324-9.

18. Jose A, Chelangara D, S S. Factors associated with anxiety and depression in chronic obstructive pulmonary disease. Int J Resc Med Sci 2016: 1074-9.

19. Xiao T, Qiu H, Chen Y et al. Prevalence of anxiety and depression symptoms and their associated factors in mild COPD patients from community settings, Shanghai, China: a cross-sectional study. BMC Psychiatr 2018; 18: 89.

20. Balcells E, Gea J, Ferrer J, Serra I, Orozco-Levi M, de Batlle J, Garcia-Aymerich J. Factors affecting the relationship between psychological status and quality of life in COPD patients. Health Quality Life Outcomes 2010; 8: 108.

21. Ryu YJ, Chun EM, Lee JH, Chang JH. Prevalence of depression and anxiety in outpatients with chronic airway lung disease. Korean J Intern Med 2010; 25: 51-7.

22. Asnaashari AMH, Talaei A, Haghighi MB. Evaluation of psychological status in patients with asthma and COPD. Iranian J Allergy, Asthma Immunol 2012; 11: 65-71.

23. Negi H, Sarkar M, Raval AD, Pandey K, Das P. Presence of depression \&amp; its risk factors in patients with chronic obstructive pulmonary disease. Indian J Med Resc 2014; 139: 402-8.

24. Dinicola G, Julian L, Gregorich SE, Blanc PD, Katz PP. The role of social support in anxiety for persons with COPD. J Psychosom Res 2013; 74: 110-5.

25. De S. Prevalence of depression in stable chronic obstructive pulmonary disease. Indian J Chest Dis Allied Sci 2011; 53: 35-9.

26. Tsai T-Y, Livneh H, Lu M-C, Tsai P-Y, Chen P-C, Sung F-C. Increased risk and related factors of depression among patients with COPD: a population-based cohort study. BMC Public Health 2013; 13: 976.

27. Waseem SMA, Hossain M, Azmi SA, Rizvi SAA, Ahmad Z, Zaidi SH. Assessment of anxiety and depression in COPD patients-A pilot study. Curr Neurobiol 2012; 3: 112-6. 